\begin{tabular}{|c|c|c|c|c|c|}
\hline MUNIBE Antropologia-Arkeologia & $n^{\circ} 67$ & $349-362$ & DONOSTIA & 2016 & ISSN 1132-2217 • eISSN 2172-4555 \\
\hline
\end{tabular}

\title{
La gestión prehistórica de un territorio en la montaña Prepirenaica: Tierra Bucho (Huesca, España)
}

\author{
Prehistoric management of a territory in the pre-Pyrenean ranges: \\ Tierra Bucho (Huesca, Spain)
}

PALABRAS CLAVES: Neolítico final; Calcolítico; Media montaña mediterránea; Cuenca del Ebro; Trashumancia GAKO-HITZAK: Azken Neolitoa; Kalkolitoa; Mendi mediterraneo ertaina; Ebroren arroa; Transhumantzia. KEY WORDS: Late Neolithic; Chalcolithic; Mediterranean Mild-Mountain; Ebro Basin; Livestock trails.

\section{Lourdes MONTES ${ }^{(1)}$, Manuel BEA ${ }^{(2)}$, Rafael DOMINGO(3), Pilar SÁNCHEZ ${ }^{(3)}$, Marta ALCOLEA(3) y María SEBASTIÁN(4)}

\section{RESUMEN}

La cuenca alta del Vero forma un pequeño valle rodeado de montañas de hasta $1.500 \mathrm{~m}$ en la zona central de la provincia de Huesca. Durante el Neolítico final y Calcolítico-Bronce antiguo, sus apenas $50 \mathrm{~km}^{2}$ registran un interesante conjunto de sitios arqueológicos: dos cuevas ocupacionales (Drólica y Carrasca), otra sepulcral (Cristales), tres dólmenes (Capilleta, Caseta de las Balanzas y Pueyoril) y tres abrigos con arte rupestre (Peña-Miel I y II y Malifeto). Las dataciones radiométricas enmarcan esta ocupación a lo largo del III milenio cal BC. Actualmente, el paisaje está cubierto por una vegetación mediterránea adaptada a un clima relativamente severo. Los ríos vecinos, Isuala y Cinca, fuerzan su paso norte-sur mediante angostos cañones que horadan los relieves calizos y dificultan el tránsito, convirtiendo este tramo del Vero en un claro pasillo que comunica el relieve más suave del Somontano con los valles pirenaicos, recorrido por las cabañeras tradicionales.

\section{LABURPENA}

Veroren goiko arroak $1.500 \mathrm{~m}$ arteko mendiz inguratutako ibar txiki bat eratzen du Huesca probintziaren erdiko eremuan. Azken Neolitoan eta Kalkolito-Brontze aro zaharrean, $50 \mathrm{~km}^{2}$-ra iristen ez den azaleran gune arkeologiko multzo interesgarri bat du: bi okupazio-leize (Drólica eta Carrasca), hilobi-leize bat (Cristales), hiru trikuharri (Capilleta, Caseta de las Balanzas eta Pueyoril) eta hiru harpe, labar-artez hornituak (Peña-Miel I eta II eta Malifeto). Datazio erradiometrikoen arabera, okupazioa cal BC III. milurteari dagokio. Orain, klima gogor samarrera egokitutako landaredi mediterraneoz estalita dago paisaia. Inguruko ibaiak, Isuala eta Cinca, kareharrizko erliebeak zulatzen dituzten eta igarotzea zailtzen duten arroila estuetatik igarotzen dira iparraldetik hegoaldera eta Veroren tarte hau Somontanoko erlieberik leunena eta Pirinioetako bailarak lotzen dituen korridore argi bihurtzen da. Abeltzain tradizionalek egiten dute bide hori.

\section{ABSTRACT}

The Upper basin of the Vero River -locally known as Tierra Bucho, for the abundance of boxwoods- forms a small, open valley surrounded by mountains up to $1500 \mathrm{~m}$ in the central area of the Pre-Pyrenean ranges, in the province of Huesca. During the Late Neolithic and the Chalcolithic/Early Bronze Age the human occupation was dense and stable, as shown by the outstanding concentration of archaeological sites: three caves, two occupational (Drólica and Carrasca) and one sepulchral (Cristales), three dolmens (Capilleta, Caseta de las Balanzas and Pueyoril) and three schematic rock-art shelters (Peña-Miel I and II and Malifeto) can be related to this phase. A coherent series of a dozen radiometric dates help to frame a recurrent human occupation of this territory along the III millennium cal BC.

Then, and even nowadays, the agricultural economy seems to be based on husbandry; farming is limited due to the poor environmental conditions, both climatic and orographic. The altitudes in the lower zones are around $850 \mathrm{~m}$, and some of the sites, like Drólica and Cristales, are at 1200 and $1320 \mathrm{~m}$ respectively. Currently, the landscape is covered by scarce Mediterranean-type vegetation, adapted to a hard climate with a precipitation index up to $800 \mathrm{~mm}$ per year; freezes are common in winters (average minimal temperatures in January of $-2,5^{\circ} \mathrm{C}$ ) and summers can be hot. The abrupt landscape of the surrounding areas, where the rivers Isuala and Cinca force their pass southwards through narrow limestone canyons, makes this basin a clear corridor to communicate the smoother southern region of the Somontano with the northern Pyrenean valleys. Husbandry is well documented along the prehistoric occupation, mainly sheeps/goats and cows, which can be linked to the presence up to modern times of livestock trails that connect the aforementioned territories. A noteworthy presence of domestic pigs among the faunal remains of Cueva Drólica is interpreted as another proof of the population stability. It can also be related to the contemporary augmentation of semi deciduous Quercus, documented in the regional palynological sequence of Estanya Lake as well as in the local wood exploitation (anthracological analysis of Drólica). The acorns of this type of oak could have fed the domestic pigs. \footnotetext{
Imontes@unizar.es.

(2) Scanner, Patrimonio e Industria. Spin-off Universidad de Zaragoza - MINECO.

(3) Universidad de Zaragoza. Área de Prehistoria. Facultad de Filosofía y Letras.

(4) Universidad de Zaragoza. Área de Geografía Física. Facultad de Filosofía y Letras
}

(1) Universidad de Zaragoza. Área de Prehistoria. Facultad de Ciencias Humanas y de la Educación. Plaza de la Constitución s/n. 22001 Huesca. 
In this sense, the spatial research is focused on two vectors: the non-accidental precise localisation of the sites (except for the caves) as well as the relationships between them; and the inner management of the domestic spaces, based on the spatial distribution of the archaeological remains in the settlements, which shall be the core of the upcoming PhD of P. Sánchez. The prehistoric territory of Tierra Bucho could be articulated around one (or perhaps more) yet-to-be found village(s) that could have been located in the low area, next to the Vero River and not very far from the dolmens. The painted sites are also interpreted as territorial landmarks, which could signal possible communication routes between the paths that, through Tierra Bucho, link the northern and southern territories. The chronological frame places the dense occupation of Tierra Bucho just after the instable period documented in multiple burials of the Ebro Basin: San Juan APL or Longar. This remote, less-productive terrain could have been occupied in the context of these violence episodes that took place in the more profitable areas of the central Ebro Basin.

The strategic condition of this territory is also well documented during the Middle Ages, when a dense grid of fortifications and watchtowers were built in order to secure the area.

\section{1.- INTRODUCCIÓN}

El territorio conocido actualmente como Tierra Bucho -por la abundancia de arbustos de boj (Buxus sempervirens), localmente llamado bucho- forma un pequeño valle abierto en el tramo alto del río Vero, afluente por la derecha del Cinca. Es una zona de media montaña, en el corazón de las Sierras Exteriores del Prepirineo central, con los caracteres kársticos propios de la montaña mediterránea (COLÓN DÍAZ, 1998) y unas condiciones climáticas ajustadas a su entorno: unos 700-800 $\mathrm{mm}$ de precipitación anual y medias de temperatura que rondan los $11-12^{\circ}$ (con mínimas y máximas anuales en torno a $-2,5^{\circ}$ y $30^{\circ}$ respectivamente). Es un área casi deshabitada en la actualidad cuyo poblamiento tradicional, que nunca debió de ser muy importante, se presenta relativamente disperso. El fondo del valle ronda los 850 metros, mientras que las alineaciones montañosas que lo cierran por sur y oeste oscilan entre 1.250 y $1.450 \mathrm{~m}$. Orográficamente la zona está relativamente aislada con respecto a los territorios meridionales (gargantas del Vero) y occidentales (cañón de Balcés) siendo más sencilla la comunicación con los valles de los ríos Ara al norte y Cinca al este. Las rutas de comunicación tradicionales (cabañeras) solventaron esas dificultades del relieve trazando sus recorridos por las crestas montañosas, relativamente llanas en este sector de las Sierras.

Durante el III milenio cal BC se desarrolla una ocupación prehistórica de cierta importancia en este limitado territorio, que se podría inscribir en un cuadrado de unos $7 \mathrm{~km}$ de lado, con una superficie algo inferior a las 5.000 ha. El río Vero lo cruza de noroeste a sureste, en un principio por un valle abierto y finalmente encajado en resaltes calizos, en todo caso menores que los que atraviesa unos kilómetros al sur formando el conocido Cañón del Vero.

En este estudio se pretende explicar la secuencia de la ocupación prehistórica de Tierra Bucho, y especialmente su concentración durante el Calcolítico. Revisando los datos procedentes de las excavaciones de los distintos yacimientos (cerámicas y demás elementos materiales, restos de fauna, el tipo de madera usado como combustible, enterramientos...) pero también la distribución de los sitios y su posible relación de interdependencia, se pretende definir el patrón de ocupación del territorio y las actividades desarrolladas por la comunidad humana que lo habitó durante este concreto periodo de la Prehistoria.

Se ha intentado un análisis geográfico bajo el marco conceptual de la Arqueología del Paisaje, que con una perspectiva global e integradora abarcara las diversas fuentes de información. No se pretendía describir un escenario estático, sino interpretar las relaciones entre personas y lugares, es decir, la caracterización de su paisaje. Con la aplicación de herramientas espaciales se intentaba cuantificar, de forma sistemática y con criterios de análisis unificados, los distintos aspectos paisajísticos de los yacimientos arqueológicos: pendiente, altitud relativa, litogeomorfología, hidrología, edafología, cuenca visual o uso potencial de territorio inmediato en el que se sitúan... Pero quizás por lo reducido de la muestra en cuanto al territorio y al número de yacimientos no se han obtenido resultados significativos.

Por ello se presenta una propuesta pluridisciplinar que vincula la ocupación de esta zona a prácticas trashumantes ganaderas. Se trata sólo de una aproximación teórica al estudio de la zona, y no tanto una exposición detallada de los yacimientos, que se sustancian en breves líneas. Una primera propuesta de interpretación ya planteaba esta posible relación entre los distintos yacimientos y las prácticas ganaderas (MONTES y DOMINGO, 2014).

\section{2.- LOS YACIMIENTOS}

En el entorno del territorio de Tierra Bucho se localizan tres yacimientos prehistóricos en cueva, tres dólmenes y tres abrigos con arte rupestre (Figura 1). A ellos se unen Cueva Foradada (800 m snm) con enterramientos visigodos (BARANDIARÁN, 1973), y unas alineaciones de piedras al modo de muros desmontados, de difícil interpretación y cronología desconocida, que en la zona llaman "La Morería" (900 m). En relación con los enterramientos de Foradada hay que citar la aparición de algunos restos de cronología visigoda/altomedieval (principalmente cerámicas) en las cuevas Drólica y de la Carrasca. También en la cueva de Lo Forato han aparecido algunos restos humanos y frag- 
mentos cerámicos, a los que no hemos podido acceder y cuya cronología desconocemos.

Los abrigos con arte rupestre son de difícil atribución cronológica. El covacho de Malifeto se localiza a 1.280 metros de altitud, en los accesos al Puntón de Asba, dominando visualmente el cordal de Sevil y el tramo alto del barranco Basender. Los abrigos de Peña Miel (I y II, vecinos entre sí a $850 \mathrm{~m}$ de altitud) se localizan en el tramo encajado del Vero, en su margen izquierda, dominando este curso y la vertiente sureste de Asba. Por la sencillez de sus motivos (cuatro barras verticales y un escaleriforme en Malifeto y algunos restos como digitaciones, manchas y trazos lineales en Peña Miel) ambas estaciones han sido consideradas como esquemáticas (BALDELLOU 1986-87 y 1991;
CALVO, 1993). En los tres abrigos, todavía en proceso de estudio, aparecen elementos propios de un arte esquemático cuya lectura (por su mal estado de conservación y simplicidad de trazos) resulta imposible (Figura 2). Estas representaciones son difíciles de clasificar crono-culturalmente, por más que sean habituales en los abrigos al aire libre de la cuenca del Vero y se atribuyan tradicionalmente a un horizonte prehistórico neolítico y/o de la Edad del Bronce.

Las cuevas ofrecen datos muy diferentes. Cueva Drólica, a $1.200 \mathrm{~m}$ de altitud, consta de dos galerías: una boca pequeña, orientada al este, da acceso al vestíbulo de la superior, donde se concentra la ocupación humana. Desechada la presencia de arte rupestre, la excavación registró un potente depósito (nivel a) atribui-

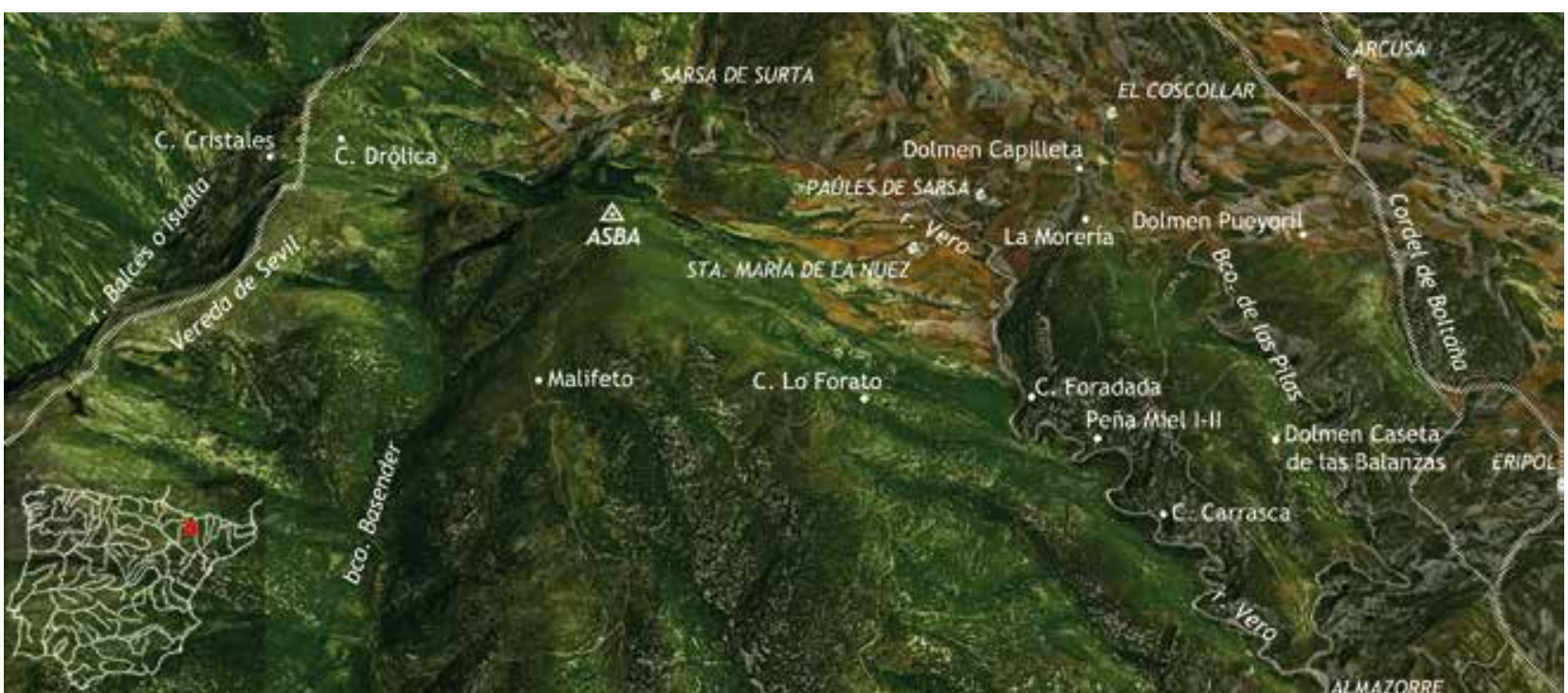

Fig. 1. Territorio de Tierra Bucho con sus yacimientos y las cabañeras que lo atraviesan. En mayúscula cursiva las poblaciones actuales. Vista oblicua a partir de Google Earth / Archaeological sites and livestock trails in Tierra Bucho area. Current villages in capital italics. Oblique view after Google Earth.
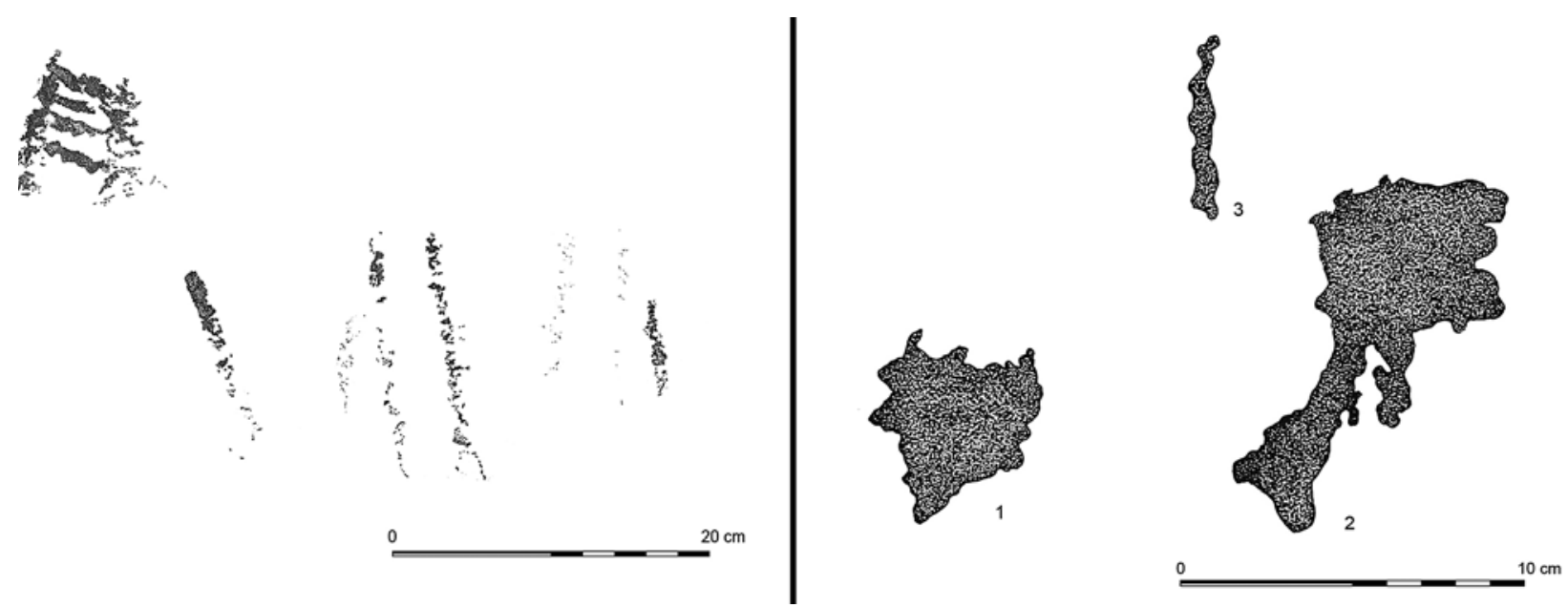

Fig. 2. Izquierda: calco de los motivos pictóricos de Malifeto. Derecha: calco de los restos de Peña Miel I. (Según Calvo, 1993) / Left: tracing of the painted motifs from Malifeto. Right: tracing of the painted motifs from Peña Miel I. (After Calvo, 1993). 

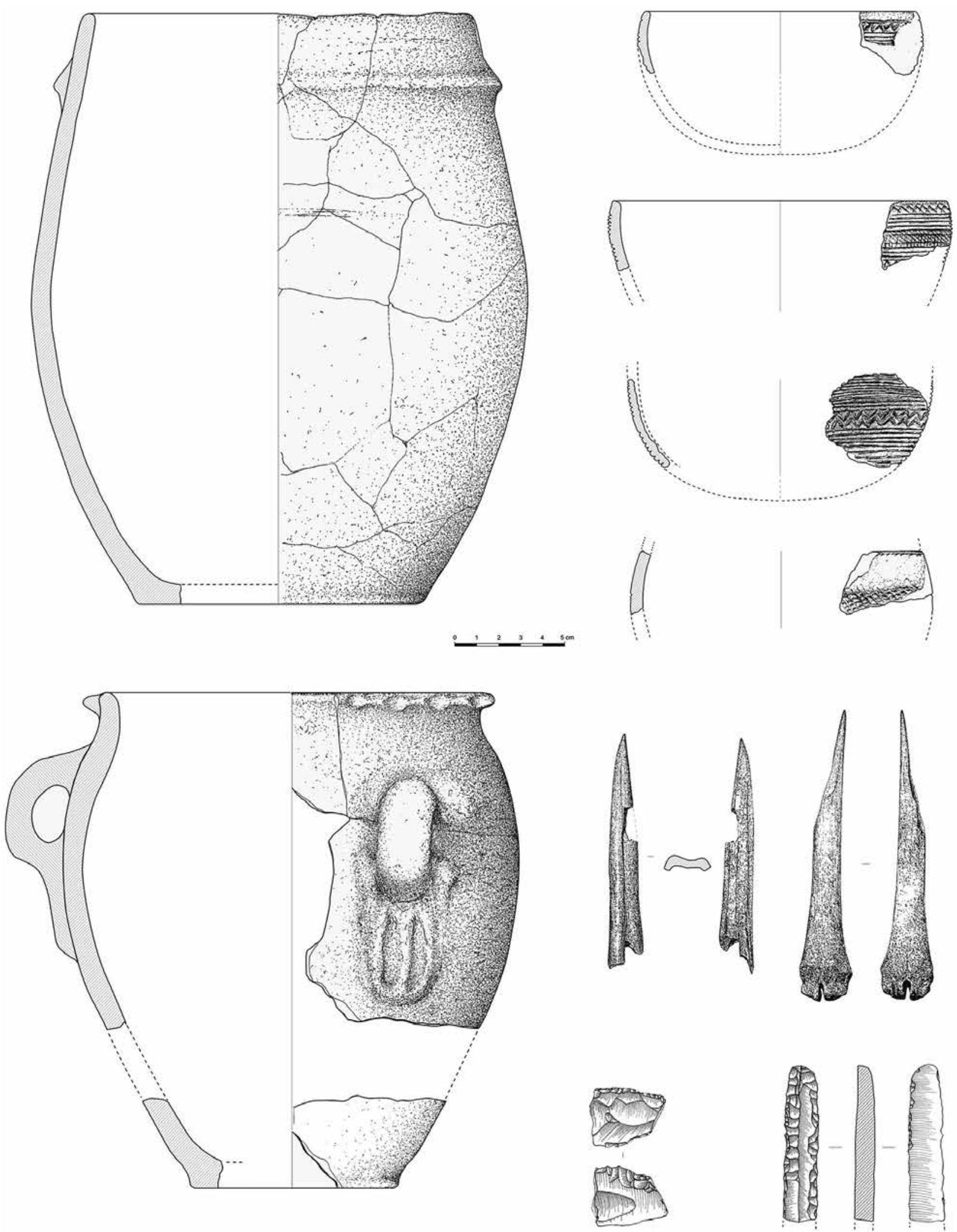

Fig. 3. Algunos materiales del nivel calcolítico de cueva Drólica (Dibujos, M.C. Sopena) / Some remains from the Chalcolithic level of Drólica cave (Drawings, M.C. Sopena). 


\begin{tabular}{|l|c|c|c|c|}
\hline LUGAR Y CAMPAÑA & TIPO MUESTRA & REF. LABORATORIO & FECHA BP & CAL BC (95\%) \\
\hline C. Carrasca 1986 & ¿Hueso? & GrN-16957 & $2145 \pm 60$ & $365-44$ \\
\hline C. Drólica 2008 & Hueso humano & Beta-318932 & $2190 \pm 30$ & $361-178$ \\
\hline C. Drólica 2007 & Carbón vegetal & GrA-37599 & $2500 \pm 30$ & $788-537$ \\
\hline C. Drólica 2006 & Carbón vegetal & GrA-33938 & $3440 \pm 35$ & $1880-1662$ \\
\hline Dolmen C. Balanzas, 1986 & Hueso humano & GrN-16052 & $3795 \pm 35$ & $2397-2061$ \\
\hline C. Drólica 2007 & Carbón vegetal & GrN-30996 & $3790 \pm 60$ & $2457-2038$ \\
\hline C. Drólica 2003 & Carbón vegetal & GrA-25757 & $3830 \pm 45$ & $2460-2146$ \\
\hline C. Drólica 2006 & Carbón vegetal & GrA-33936 & $3975 \pm 35$ & $2579-2349$ \\
\hline C. Drólica 2006 & Carbón vegetal & GrA-33935 & $4000 \pm 35$ & $2619-2462$ \\
\hline C. Cristales 2001 & Hueso humano & GrN-26967 & $3900 \pm 100$ & $2834-2041$ \\
\hline C. Drólica 2007 & Carbón vegetal & GrA-38063 & $4105 \pm 30$ & $2864-2506$ \\
\hline C. Cristales 2007 & Hueso humano & GrA-38062 & $4125 \pm 30$ & $2867-2581$ \\
\hline Dolmen La Capilleta 1987 & Hueso humano & GrN-16051 & $4360 \pm 35$ & $3089-2901$ \\
\hline C. Cristales 2007 & Hueso humano & GrA-38061 & $4370 \pm 30$ & $3089-2907$ \\
\hline C. Drólica 2006 & Carbón vegetal & GrA-33914 & $5855 \pm 40$ & $4828-4609$ \\
\hline
\end{tabular}

Tabla 1: Dataciones C14 de los yacimientos de Tierra Bucho, ordenados por antigüedad. Las fechas se han calibrado con IntCal 2013 (Reimer et al., 2013) / Chronologycally ranged C14 dates from Tierra Bucho archaeological sites. Calibrated by IntCal 2013 (Reimer et al., 2013).

do al Calcolítico campaniforme - Bronce antiguo a partir de los materiales cerámicos recuperados (Figura 3) y de las dataciones (Tabla I). Entre los materiales destaca un gran recipiente con decoración campaniforme y una capacidad por encima de los 60 litros, de exquisita factura. Otros indicios aislados permiten constatar una temprana visita en el Neolítico, ca. 4700 cal $\mathrm{BC}$, y algunas estancias posteriores, presumiblemente de corta duración: en la Primera Edad del Hierro, en época ibérica (de tipo funerario) y en época visigoda/ altomedieval. Todos estos vestigios más modernos parecen haber sido afectados por el acondicionamiento reciente del vestíbulo y aparecen como intrusiones en el depósito calcolítico (MONTES et al., 2001; MONTES y MARTÍNEZ BEA 2006 y 2007).

La cueva de los Cristales se abre sobre el último escalón de los cantiles calizos del barranco de Balcés, a unos $1.320 \mathrm{~m}$ de altitud y orientada al oeste. Es una pequeña cavidad con dos salas unidas por un angosto tubo que fue excavada a la vez que Drólica por el mismo equipo, dada su proximidad (MONTES y MARTíNEZ BEA, 2006: 310). La cámara interior fue utilizada como lugar de enterramiento. Se han identificado al menos 8 individuos diferentes (ALCONCHEL, 2013) cuyas dataciones (Tabla I) sugieren el inicio de su uso algo antes de la fase campaniforme visible en cueva Drólica. Escasos y anodinos fragmentos de cerámica lisa acompañaban los restos humanos.

La cueva de la Carrasca se localiza a 825 m de altitud, directamente colgada sobre el cauce del Vero y próxima los abrigos de Peña Miel. En la actualidad hay que descolgarse desde la parte alta del cantil, al haberse desplomado parte de éste. Es una cavidad sencilla, con la boca orientada al norte y una galería con dos codos de apenas 25 metros de recorrido total.
La excavación de su depósito, muy alterado de antiguo (ESCO y CALVO, 1986), entregó sobre todo materiales cerámicos que permiten identificar distintos momentos de ocupación (Figura 4): algunos fragmentos impresos de tipo neolítico a los que acompañan varias láminas de sílex, dos geométricos y un taladro; un importante lote de cerámicas del Calcolítico-Bronce antiguo y un interesante conjunto de cronología tardorromana/visigoda. Algunos restos humanos indican un uso también funerario, cuya cronología no se ha precisado: con los datos disponibles no se puede discernir el carácter humano o de fauna de una muestra de hueso datada en época ibérica (Tabla I). Por último, la mencionada cueva de Lo Forato, situada en la ladera sureste del Asba sobre la orilla derecha del Vero (1.020 m), cabe también en este relato por la aparición de un hacha pulimentada al pie de su boca (BARANDIARÁN, 1973: 11), quedando por determinar la cronología de los restos recuperados.

Tres sepulturas megalíticas completan la serie de sitios: todas ellas responden al tipo de cámara simple cubierta por un túmulo de piedras que se conserva relativamente bien en Pueyoril (sin excavar, $860 \mathrm{~m} \mathrm{snm}$ ) y en la Caseta de las Balanzas (870 m), habiendo desaparecido casi al completo en el caso de la Capilleta (877 m). El empleo de estas estructuras parece extenderse durante todo el III milenio cal BC, según las dataciones obtenidas en estos dos últimos (CALVO 1991a, 1991b). Unas pocas cuentas de collar discoidales, cilíndricas y dentalia, conchas perforadas, algún botón de perforación en $\mathrm{V}$ y escasos elementos líticos acompañaban a los pobres restos humanos (dientes, falanges y otros huesos pequeños) que se recuperaron en las excavaciones, pues estos recintos habían sido históricamente alterados y expoliados. 


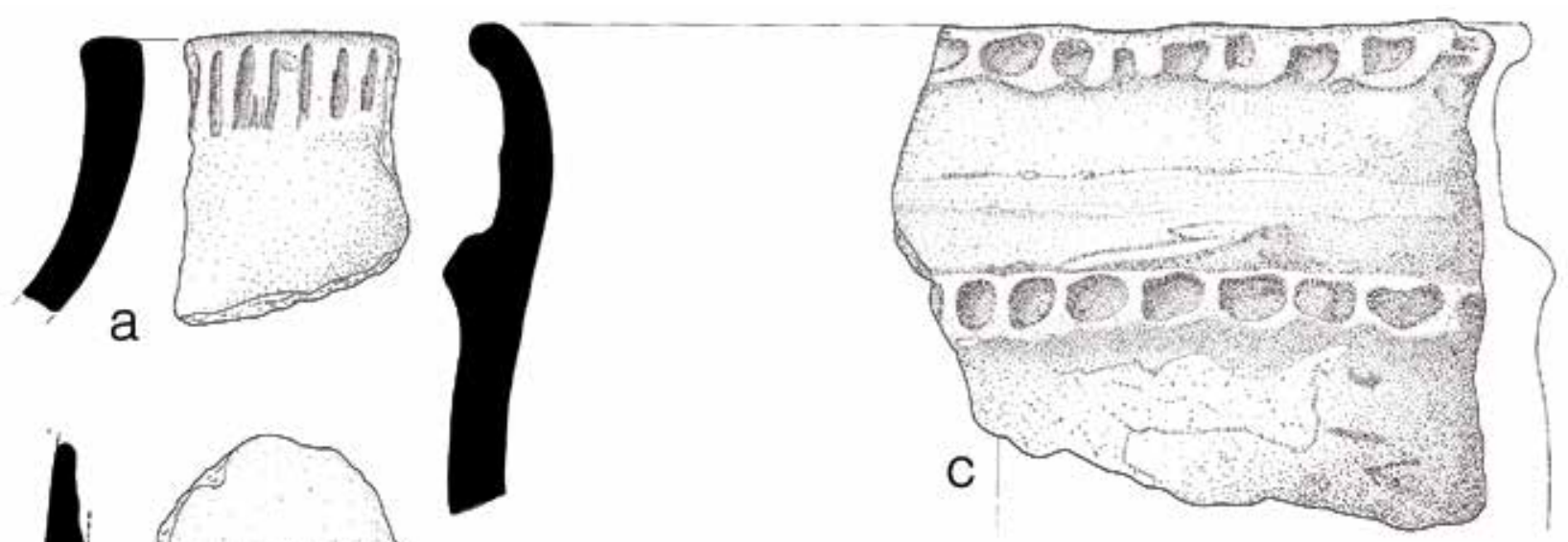




\section{3.- EL MARCO AMBIENTAL}

Alrededor del 4000 cal BC tuvo lugar una fluctuación climática global debida a una reorganización de las circulaciones atmosférica y oceánica que repercutió también en el área pirenaica y prepirenaica. El progresivo enfriamiento de la superficie marina en el Cantábrico conllevó una paulatina reducción en la intensidad de los frentes atlánticos que alcanzaban los Pirineos, permitiendo así una expansión gradual del clima Mediterráneo en los Pirineos Centrales. Este proceso no se manifiesta con claridad en los registros paleoambientales hasta aproximadamente el 2800 cal BC, tal como refleja la secuencia polínica del ibón pirenaico de la Basa de la Mora, a
1.900 m (PÉREZ-SANZ et al., 2013) donde los bosques pasaron de ser predominantemente caducifolios a estar dominados por Pinus, mientras que en la serie polínica de Estaña (680 m) al sur de la Ribagorza oscense, este cambio apenas se manifiesta (PÉREZ-SANZ, 2014). A partir de este momento (Holoceno Final) se documenta en Europa meridional una tendencia hacia una mayor aridez, reconocida por un descenso notable de las mesófitas y una bajada de nivel en los lagos. Ambas secuencias reflejan este proceso mediante el descenso del nivel del agua, una brusca expansión del quejigo, un ligero aumento de los Quercus perennes y reducción de los pinares a media altitud y el aumento de taxones como Juniperus y Artemisia en las zonas elevadas (Figura 5).

OxCal v4.2.4 Bronk Ramsey (2013); r5 IntCal atmospheric curve (Reimer et al. 2013)
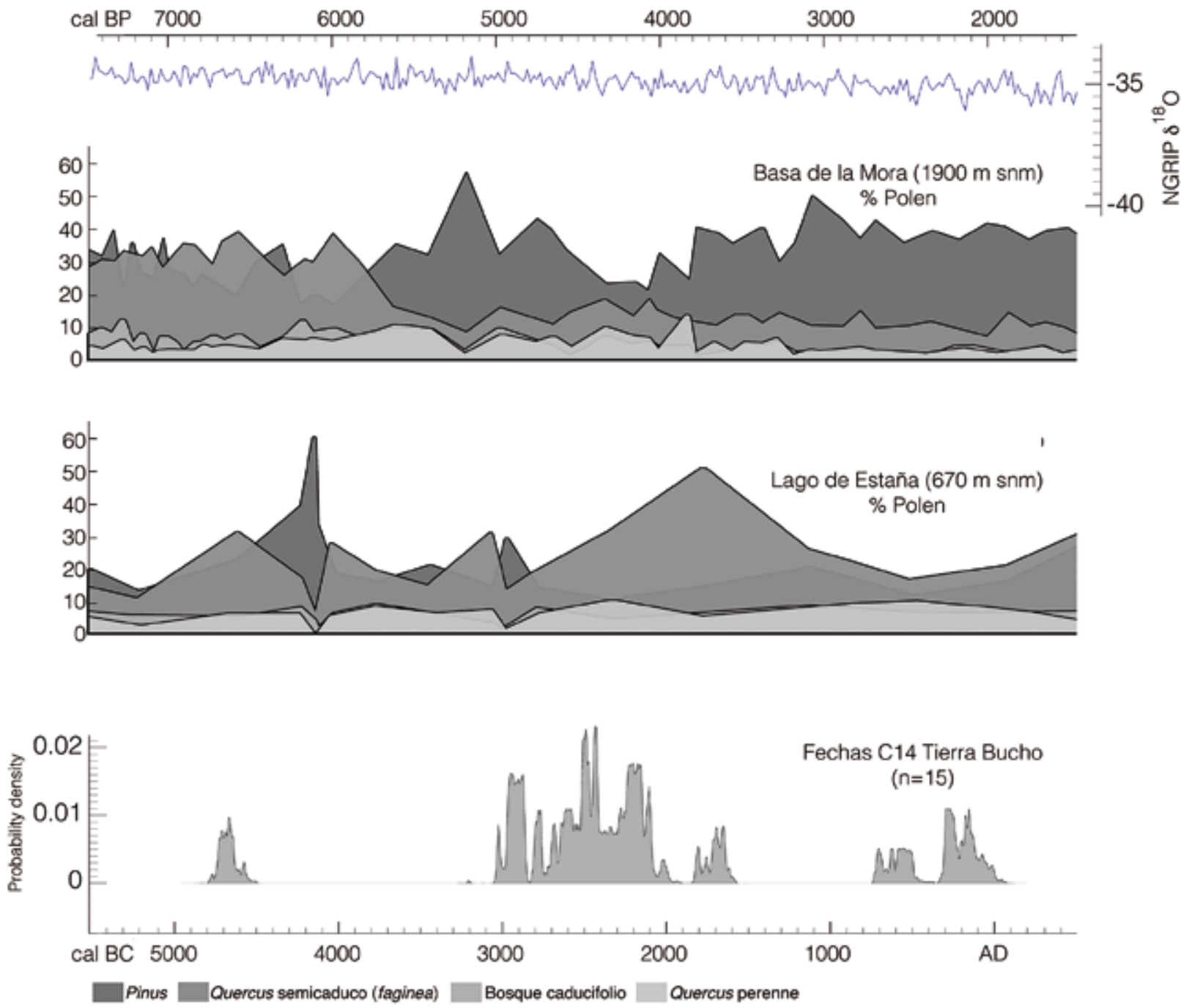

Fig. 5. Representación gráfica de las fechas radiocarbónicas de Tierra Bucho en años cal BC con 20 (IntCal 2013, Reimer et al., 2013) comparadas con el modelo cronométrico NGRIP. En el centro, evolución de algunos taxones (Pinus, Caducifolios y Quercus) en las secuencias paleoambientales de Basa de la Mora (Pérez-Sanz et al. 2013) y Estaña (Pérez-Sanz, 2014) / Graphical representation of radiocarbon dates from Tierra Bucho sites in years cal BC with 20 (IntCal 2013, Reimer et al., 2013) compared with the NGRIP chronometric model. Center: evolution of selected taxa (Pinus, Deciduous and Quercus) in the paleoenvironmental sequences of Basa de la Mora (Pérez-Sanz et al. 2013) and Estaña (Pérez-Sanz, 2014). 
En ninguno de los yacimientos excavados en Tierra Bucho se han tomado muestras de polen: el carácter poroso y parcialmente alterado de los sedimentos de las cuevas (Drólica y Carrasca) y la mínima extensión del sedimento conservado en los dólmenes (Capilleta y Caseta de las Balanzas) no lo aconsejaba. Pese a ello, el espacio de habitación de cueva Drólica ofrece información acerca del entorno forestal. En su nivel a se localizan diversas estructuras de combustión que reflejan el uso prolongado de la cueva. A causa de las labores de limpieza y acondicionamiento del espacio de hábitat, los carbones aparecen dispersos en el sedimento reflejando varios momentos de quema de leña. Estos hogares utilizaron como combustible principalmente la madera de las especies vegetales presentes en el entorno del yacimiento, proporcionando una valiosa información paleoambiental (BADAL, 1987, 1992; CHABAL, 1992).

El estudio antracológico de Drólica ha permitido documentar durante el Calcolítico la presencia de un mínimo de 9 taxones entre los que se han alcanzado diferentes grados de determinación (especie, género o familia): Acer sp., Buxus sempervirens, Corylus aveIlana, Fraxinus sp., Pinus tipo sylvestris/nigra, Quercus ilex/coccifera, Quercus sp. caducifolio, Rosaceae/Maloideae (Tabla II). Sin duda, las especies mejor representadas en este conjunto son las quercíneas de tipo caducifolio y semicaducifolio (55\%). Por razones ecológicas, se puede aventurar que se trate de la variedad Quercus faginea (quejigo o cajico) de tipo marcescente, que en la actualidad forma un denso bosque junto con la carrasca en el entorno inmediato de la cueva. Aunque con porcentajes muy inferiores, es importante también la presencia de pinos de tipo albar/salgareño típicos de la media montaña $(22,3 \%)$, arces $(6,6 \%)$ y boj $(5,6 \%)$, el arbusto más significativo del Pirineo ibérico por su extensión y ubicuidad. También se constata la presencia puntual de taxones higrófilos que formarían parte del bosque de ribera o crecerían en orlas forestales.

\begin{tabular}{|l|c|c|c|}
\hline \multicolumn{1}{|c|}{ Adscripción cultural } & CALCOLÍTICO & \multirow{2}{*}{ E. HIERRO } & \multirow{2}{*}{ TOTAL } \\
\cline { 1 - 2 } TAXONE de contexto & Disperso & Hogar & \\
\hline Acer sp. & $\mathrm{N}(\%)$ & $\mathrm{N}(\%)$ & $\mathrm{N}(\%)$ \\
\hline Buxus sempervirens & $13(6,6)$ & & $13(4,7)$ \\
\hline Corylus avellana & $11(5,6)$ & $4(5,2)$ & $15(5,5)$ \\
\hline Fraxinus sp. & $3(1,5)$ & & $3(1,1)$ \\
\hline Pinus tipo sy/vestris/nigra & $44(22,3)$ & & $1(0,4)$ \\
\hline Quercus ilex/coccifera & $1(0,5)$ & & $12(15,3)$ \\
\hline Quercus sp. caducifolio & $108(54,8)$ & $73(94,8)$ & $181(66,0)$ \\
\hline Rosaceae/Maloideae & $1(0,5)$ & & $1(0,4)$ \\
\hline Indeterminado & $3(1,5)$ & & $3(1,1)$ \\
\hline Indeterminable & $14(7,1)$ & & $14(5,1)$ \\
\hline Total fragmentos & $197(100)$ & $77(100)$ & $274(100)$ \\
\hline Total taxones & 9 & 2 & 9 \\
\hline
\end{tabular}

Tabla 2: Cueva Drólica. Vegetación identificada (taxones) a partir de los carbones recuperados / Drólica cave. Identified vegetation (taxa) from the recovered charcoals.
En un segundo lote de carbones procedentes de un enorme hogar datado en la Primera Edad del Hierro (ca. 650 cal BC) se ha constatado la presencia casi exclusiva de un solo tipo de leña, como es habitual en los hogares bien conservados: en este caso Quercus de tipo caducifolio o semicaducifolio (ca. 95\%) y algo de boj. Ambas especies, bien documentadas en el Calcolítico, continúan presentes en la zona.

En resumen, el entorno forestal de estos yacimientos estaría caracterizado por la presencia de quejigares acompañados de taxones submediterráneos que formarían parte del estrato arbóreo y arbustivo. Este entorno ofrecería abundantes y variados recursos vegetales explotados con diversos fines, como el aprovisionamiento de combustible de gran calidad o el ramoneo del ganado, tal como sugiere la cabaña ganadera documentada en cueva Drólica.

\section{4.- EL DESARROLLO DE LA OCUPACIÓN PRE- HISTÓRICA DE TIERRA BUCHO. HIPÓTESIS IN- TERPRETATIVA}

Los datos arqueológicos muestran la consolidación del poblamiento de Tierra Bucho en el Calcolítico. La cuestión está en determinar el porqué de este proceso en este momento. Otros materiales evidencian estancias previas y posteriores, que también se revisan y analizan en este texto. Aunque los datos disponibles puedan parecer numerosos, este territorio no debe ser considerado como excepcional: más bien son consecuencia de una coincidencia de actuaciones arqueológicas en distintas etapas (años 80 y primera década de este siglo) mientras que otras zonas no se han trabajado con la misma intensidad.

Está constatada la frecuentación humana de la zona casi dos milenios antes del Calcolítico: la fecha ca. 4700 cal BC de uno de los carbones localizado bajo una costra en la zona profunda de Drólica parece atestiguarlo (MONTES y MARTÍNEZ-BEA, 2006: 299) y los escasos materiales de apariencia neolítica (cerámicas impresas, geométricos...) de la Cueva de la Carrasca apoyarían esta idea (Figura 4). Pero hasta inicios del III milenio cal BC no se acumulan las dataciones disponibles (Tabla I, Figura 5) y en los sitios excavados no hay más restos claramente neolíticos que los mencionados.

Se pueden interpretar estos vestigios neolíticos como resultado de una primera estancia en la zona, con una habitación restringida que prefirió asentarse junto al cauce del Vero (cueva de la Carrasca) al tiempo que reconocía el territorio circundante: el carbón de cueva Drólica podría relacionarse con el uso de una antorcha para iluminar el interior de las galerías. La fecha obtenida se aproxima a las del estrato II de la Puyascada (BALDELLOU, 1987: ca. 4850 y 4400 cal BC, también sobre carbón) o las de la fase II de Trocs (ROJO et al., 2013: ca. 4400 cal BC, sobre semillas) y permite relacionar este episodio con la explotación estival de los pastos de altura pirenaicos y pre-pirenaicos por los pastores neolíticos (Figura 6): Puyascada abre su boca 


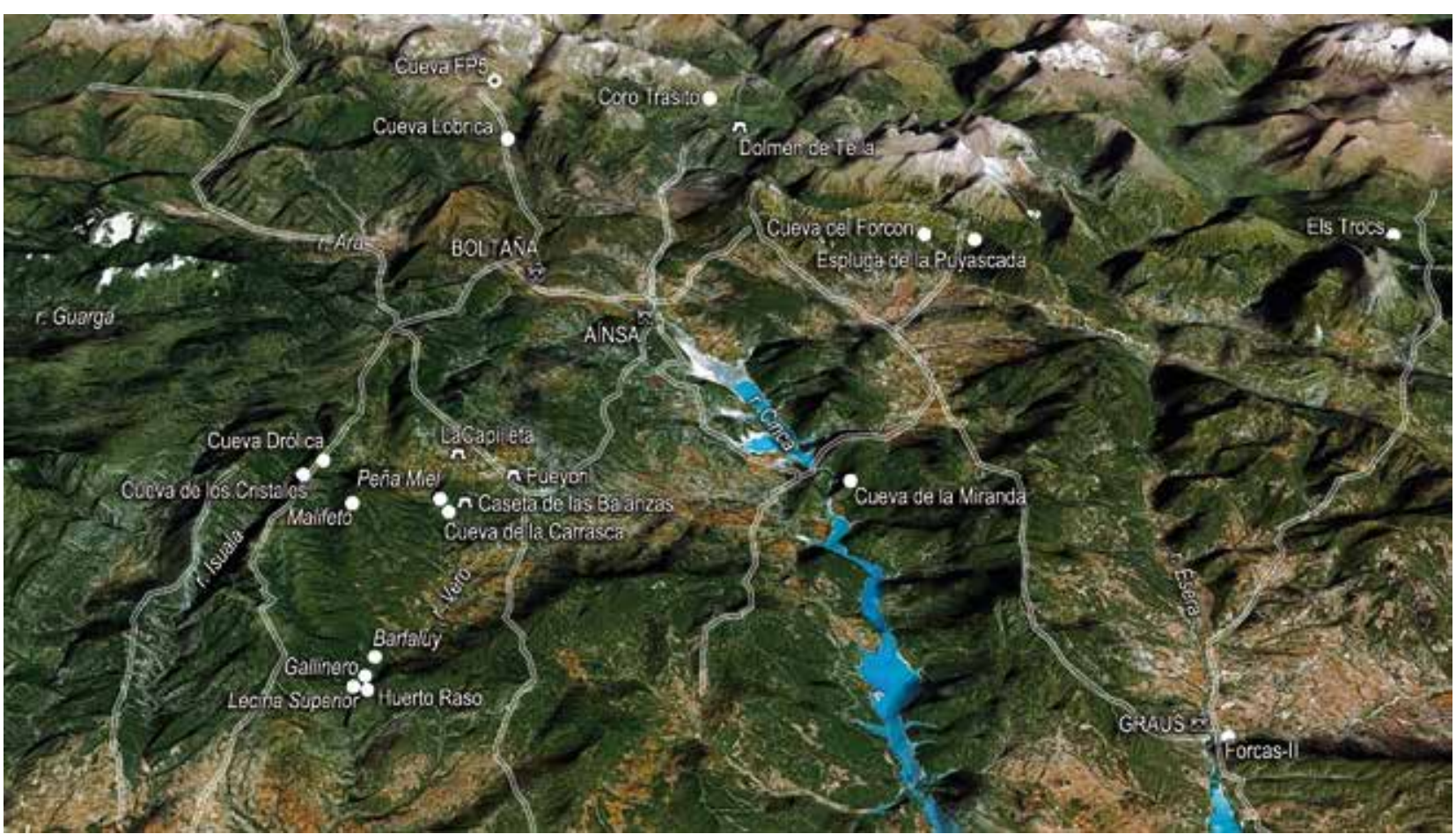

Fig. 6. Tierra Bucho y yacimientos neolíticos del oriente oscense, con el trazado de las principales cañadas históricas. Vista oblicua a partir de Google Earth / Main livestock trails and Neolithic sites from Eastern Huesca province and Tierra Bucho area. Oblique view after Google Earth.

a 1.320 m en la cara sur de Sierra Ferrera, mientras que Trocs se localiza a $1.564 \mathrm{~m}$ en el entorno del Turbón (ROJO et al., 2014).

La búsqueda de este recurso concreto, los pastos de verano, pudo estar detrás de esta primera incursión en Tierra Bucho, que habría dejado los escasos vestigios materiales de la cueva de la Carrasca (825 m) y sólo unos carbones en Drólica (1.200 m). A este respecto, hay que comentar que los posteriores ocupantes calcolíticos de la cavidad acondicionaron su solera mediante una acumulación de lajas calizas cuya potencia oscila entre los 15 y los $40 \mathrm{~cm}$, para regularizar y aislar de la humedad el suelo de ocupación. Estos trabajos pudieron desmantelar los restos de esta supuesta ocupación anterior -de la que no se ha hallado vestigio material alguno que permita rastrearla- o bien cubrirlos por completo: la excavación sondeó este suelo aleatoriamente en algunos cuadros hasta llegar a la roca madre sin que aparecieran restos arqueológicos. En la cueva de la Carrasca, los restos líticos de carácter neolítico (láminas, taladro, geométricos) corresponden en su casi totalidad a la variedad conocida como tipo Monegros (GARCÍA-SIMÓN y MANDADO, 2014), lo que vincula su ocupación con las tierras situadas al sur, tal como se ha propuesto también para Puyascada o Trocs (MAZZUCO et al., 2014).

El territorio de Tierra Bucho es recorrido por diversas cabañeras históricas (Figura 7) que en nuestra opinión (MONTES et al., 2016) están fosilizando rutas prehistóricas que no necesaria y exclusivamente hay que vincular con tránsitos ganaderos: Drólica se relaciona con la actual cabañera que recorre el cordal de Sevil (cañada real Broto-Mequinenza) y la Carrasca con el cordal de Boltaña (Boltaña-Mequinenza). Aunque estas cabañeras históricas no tienen que replicar exactamente los caminos antiguos, su trazado no debía diferir mucho. La distribución de los yacimientos neolíticos "de nueva planta" en cuevas o abrigos del oriente oscense jalonan precisamente estas vías de acceso hacia el norte (Figuras 6 y 7 ). Son yacimientos situados a cotas altas, que se datan a lo largo del $\mathrm{V}$ milenio, y que se pueden identificar con nuevas prácticas ganaderas, se hayan descrito/identificado o no en su interior niveles de tipo fumier (localmente conocidas como femeras). Todos ellos muestran una cierta uniformidad en sus decoraciones cerámicas, con gran profusión de producciones impresas entre las que son minoría las ejecutadas con Cardium (ALDAY et al., 2012; MONTES y ALDAY, 2012).

Es posible realizar algunas apreciaciones de carácter general, no determinantes, que pueden poner en relación los conjuntos rupestres de Malifeto y Peña Miel con el territorio en el que se insertan y dentro de este con el recorrido de los caminos/cañadas (Figura 1). En relación a éstas, y sin que se pueda establecer una asociación inequívoca, merece la pena destacar la ubicación de ambos conjuntos rupestres -distantes apenas $3 \mathrm{~km}$ lineales entre sí, en una disposición axial horizontal-, que pudieron ejercer una función de control visual en cada uno de los barrancos (ejes de comuni- 


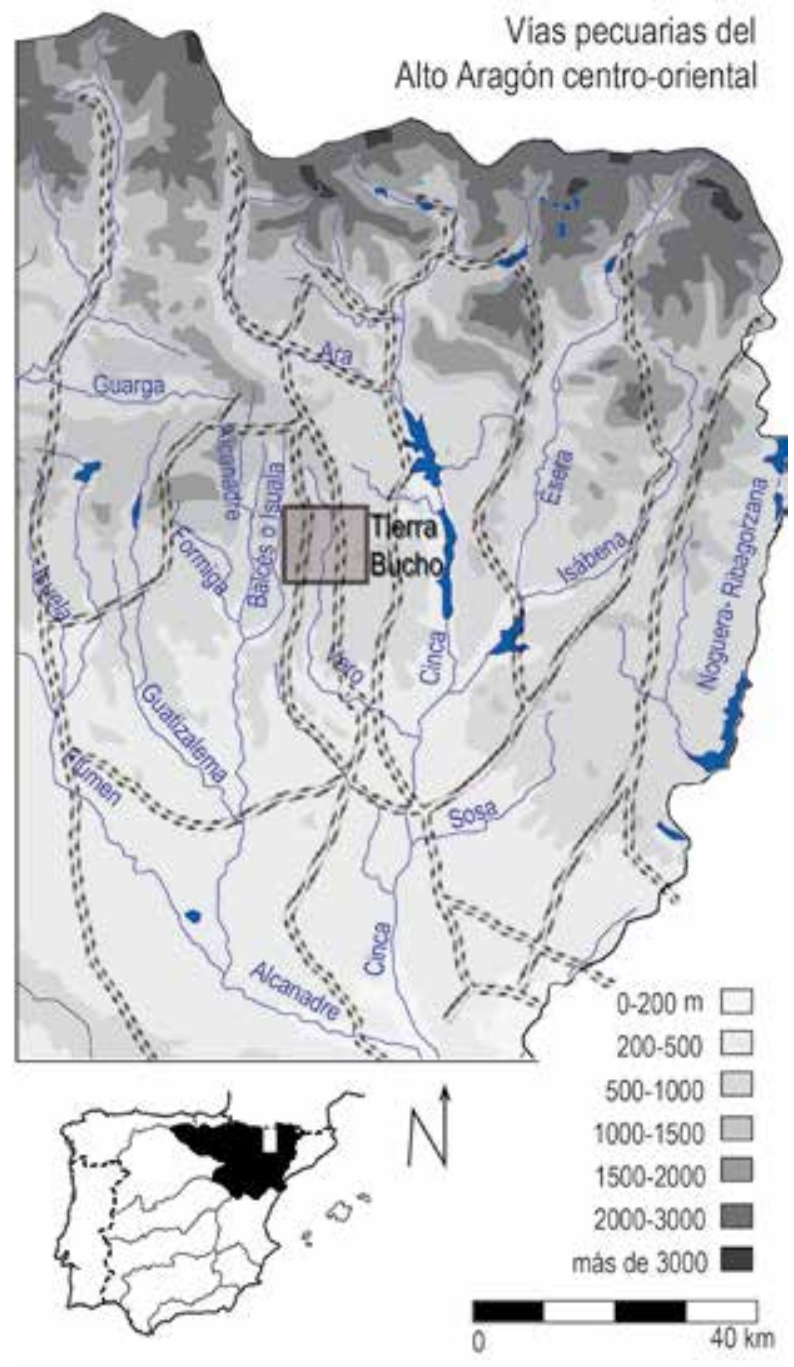

Fig. 7. Situación de Tierra Bucho con respecto a las principales cañadas históricas del sector centro-oriental de la provincia de Huesca (a partir de Pallaruelo 1988 e idearagon.aragon.es) / Tierra Bucho location in respect to the main historic livestock trails from the central-eastern part of Huesca province (drawn after Pallaruelo 1988 and idearagon.aragon.es)

cación norte-sur) donde se localizan (Malifeto en Basender y Peña Miel I-II sobre el Vero) y de los caminos/ cañadas vecinos. De este modo, se podría plantear una relación entre ambos conjuntos quizá como marcadores de una ruta transversal (este-oeste) entre las dos vías de comunicación principales (norte-sur): en esta zona de Tierra Bucho las actuales cañadas Broto-Mequinenza y Boltaña-Mequinenza reducen notablemente (unos 8 $\mathrm{km}$ ) la distancia entre sus trazados. Acerca del carácter elemental de estas figuraciones, y más allá de su interpretación general como posibles elementos de cómputo, imposible de determinar (BALDELLOU et al., 2009: 79), resulta inviable precisar su significado y asegurar su relación espacial, cultural y cronológica con los otros componentes del paisaje antropizado de Tierra Bucho, e incluso entre sí. A la imprecisión ofrecida por los restos pictóricos (por su simplicidad y mal estado de conser- vación) hay que añadir, en ambos conjuntos rupestres, la ausencia de yacimiento arqueológico asociado.

La construcción y primer uso de los monumentos funerarios (dólmenes) se relaciona tradicionalmente con el mundo neolítico, pero los pocos restos recuperados en la Capilleta y la Caseta de las Balanzas, para los que se ha supuesto una reutilización en época calcolítica (ANDRÉS, 1997), no permiten precisar la cronología de su origen. Parece probable que haya que retrasarlo hasta momentos anteriores, quizás en un Neolítico pleno, y siempre previos a la datación obtenida en la Capilleta (ca. 3000 cal BC), relacionados con el levantamiento de un poblado (o más) al aire libre que no hemos localizado. La presencia de hasta tres monumentos diferentes traduce una población de cierta entidad y asentada, que no casa con los pobres vestigios neolíticos documentados en las cuevas.

La intensificación de la llegada de estas gentes a la media montaña podría relacionarse con los movimientos de población que se producen en el último tercio del IV milenio cal BC en el Valle del Ebro: quizás derivados de un crecimiento demográfico importante que convirtió en insuficientes los recursos disponibles e impulsó la toma de conciencia de la alteridad y, en consecuencia, movimientos de conquista. Hay constancia de importantes enfrentamientos bélicos entre distintos grupos, que hoy adquieren visibilidad arqueológica mediante la aparición de fosas con enterramientos colectivos/ múltiples: el covacho alavés de San Juan ante Portam Latinam (VEGAS et al., 1999; VEGAS, 2007) o el hipogeo navarro de Longar (ARMENDÁRIZ et al., 1994), datados ambos ca. 3200 cal BC y con indicios claros de muertes violentas. Algo más tardía (ca. 2700 cal BC), la fosa riojana de la Atalayuela en Agoncillo, que contiene los tres tipos de producciones campaniformes, parece reflejar la persistencia de la inestabilidad en las tierras bajas (BARANDIARÁN, 1978; HARRISON, 1988; ANDRÉS y BARANDIARÁN, 2004). La destruida sepultura de La Varillaza de Zuera, en el valle bajo del río Gállego (VILLAR, 2006: 263-265) ha sido recientemente datada ca. 3000 cal BC (Beta-383756, 4390 30 BP); junto con las antiguas citas sobre posibles fosas colectivas prehistóricas de La Cartuja de las Fuentes en Sariñena y de la Sierra de Alcubierre (ANDRÉS, 1992 y 1998; ANDRÉS y BARANDIARÁN, 2004) en el tramo inferior del Alcanadre, amplían las evidencias de inseguridad al tramo aragonés del Valle del Ebro. Para estos autores, estos movimientos/choques de grupos en el Ebro podrían responder no sólo a una dinámica interna, sino en última instancia ser la consecuencia del extraordinario desarrollo demográfico de las regiones del sudeste francés cuyos grupos excedentarios habría recibido la cuenca ibérica, generando una importante inestabilidad social y enfrentamientos entre las poblaciones locales y las gentes recién llegadas (ANDRÉS, 1998; ANDRÉS y BARANDIARÁN, 2004).

Fuera por ese estímulo externo, fuera como consecuencia de la propia demografía ibérica, la inesta- 
bilidad de las zonas bajas o la necesidad de nuevas tierras pudo llevar a finales del IV milenio (¿o antes?) a un grupo humano hasta Tierra Bucho, donde se instalaría durante un milenio largo, aprovechando los recursos de la zona para subsistir. El grupo levantaría un poblado de localización desconocida y los tres dólmenes mencionados, que apuntan quizás, como ya se ha dicho, hacia más de un establecimiento. Cada uno de ellos podría responder a un poblado diferente, pero también, la Capilleta y Pueyoril podrían funcionar como marcadores territoriales de un mismo enclave, situado en el entorno de la actual población de El Coscollar; no así la Caseta de las Balanzas, que se distancia y aparta de esta zona. Los tres comparten su situación en ligeros resaltes $( \pm 870 \mathrm{~m})$ que destacan sobre el fondo del valle, lo que apunta hacia su funcionalidad como marcadores territoriales además de como recintos funerarios.

Las tierras Ilanas de la parte baja del valle permitirían una agricultura basada en el cereal, que se rastrea en un importante lote de dientes de hoz recuperados en la cueva de la Carrasca y en la profusión de hachas pulimentadas localizadas por toda la zona, quizás relacionadas con la obtención de combustible leñoso, pero también con tareas de deforestación para conseguir espacios libres aptos para el cultivo. Barandiarán (1973) cita en la detallada introducción al estudio de Cueva Foradada cinco ejemplares de la vecindad de Santa María de la Nuez, entre ellas la aparecida al pie de la cueva de Lo Forato, a las que se pueden añadir seis más localizadas en los vecinos núcleos de Las Bellostas o Bagüeste (MONTES y MARTÍNEZ BEA, 2006).

Esta agricultura se acompañaría de una importante cabaña ganadera, que en los recuentos preliminares de Drólica efectuados por P. Castaños muestra el habitual dominio de ovicaprinos (45\%) y proporciones similares entre cerdos y bóvidos (25\%). Se trata una economía con domesticación plena que conserva prácticas esporádicas de caza: ciervo, jabalí, liebre... La fragmentación sistemática de los huesos, las marcas de descarnamiento y la presencia de huesos quemados indica una tafocenosis de origen antrópico. La muestra, compuesta sólo por mamíferos (sin aves y otros grupos de vertebrados) sugiere una ocupación intensa de la cueva por el grupo humano, que no permitió intrusiones de roedores, anfibios o pequeños reptiles. La fauna recuperada en la cueva de la Carrasca queda pendiente de estudio.

La explosiva expansión del quejigo (Quercus faginea) documentada en Estaña, que se identifica también en la determinación antracológica de Cueva Drólica con un 55\% de taxones de Quercus caducifolio y/o semicaducifolio, podría explicar el importante peso del cerdo en esta cabaña ganadera. Los quejigos producen bellotas de calidad inferior a las de otros tipos de Quercus, pero a cambio la maduración de los frutos es más temprana, a principios del otoño: los cerdos podrían ser alimentados con este recurso en montaneras de verano/otoño en todo el territorio de Tierra Bucho enlazando la producción de sus bellotas con otras posteriores, incluso en las laderas de la parte alta, donde cueva Drólica sería aprovechada como refugio por los cuidadores de las piaras. Esta maduración temprana permitiría combinar la presencia del cerdo con otras especies deudoras de los pastos herbáceos de los espacios abiertos de altura como ovejas y vacas (Collado del Mesón, Puntón de Asba...) y por supuesto con las poco exigentes y omnipresentes cabras.

Dada la escasa aptitud del ganado porcino para la trashumancia, su presencia apuntala también un modelo de ocupación del territorio bien consolidada en esta época, basado en hábitats de tipo permanente. Es difícil definir como tales lugares las cuevas: Drólica por las deficientes condiciones que ofrece para la habitación (altitud, humedad, baja temperatura interior...) y la Carrasca por su compleja forma de acceso (que en la actualidad requiere de técnicas de escalada avanzadas) y tamaño. Podrían en cambio ser asentamientos especializados de un(os) poblado(s) todavía no documentado(s), cuyo ganado accedería a estas zonas altas en un régimen de transterminancia o trashumancia altitudinal de ámbito local. En este tipo de desplazamientos cortos, verticales, dentro del mismo valle, el ganado inverna en las zonas bajas estabulado o semiestabulado, y en verano sube a los pastos de altura y aunque hay noticias de trashumancia en el Pirineo aragonés desde el s. XVI, “...la trasterminancia o trashumancia ascendente de corto recorrido se ha venido practicando en los pueblos y aldeas situados entre las Sierras Interiores y las Exteriores -es decir, en el territorio que suele conocerse como Pre-pirineo- desde tiempo inmemorial" (PALLARUELO, 1993: 41).

En una perspectiva territorial mas amplia sobre movimientos de larga distancia, no reñidos con los supuestos desplazamientos locales, Drólica podría dar acceso a la ruta de comunicación que por el Cordal de Sevil permite salvar los intransitables cañones del río Vero y poner en contacto la cuenca Boltaña-Aínsa que se forma en la confluencia entre los ríos Cinca y Ara con las tierras llanas del Somontano, al sur. La cueva de la Carrasca, por su parte, marcaría la salida directa de Tierra Bucho aguas abajo del río Vero, hacia un territorio donde abundan los vestigios del tránsito humano prehistórico (abrigos con arte rupestre). Desde una perspectiva a mayor escala de los desplazamientos prehistóricos no necesariamente pastoriles (MONTES et al., 2016), Tierra Bucho presenta una situación a medio camino entre las tierras Ilanas del centro de la Cuenca del Ebro y algunos pastos de altura en el Pirineo explotados desde los inicios de la ganadería (Figura 7). En este sentido apuntan el depósito neolítico tipo fumier de Coro Trasito a más de $1.500 \mathrm{~m}$ en Tella, que ha proporcionado recientemente tres fechas entre ca. 5100 y 4600 cal BC (CLEMENTE et al., 2014) y las cerámicas impresas de Cueva Lobrica, colgada en las paredes del cañón de Añisclo a 900 m (REY et al., 2014). 
Quizás estos supuestos desplazamientos motivaron que los primeros ganaderos neolíticos conociesen el territorio de Tierra Bucho, aunque por el momento es difícil identificar inequívocamente esos vestigios con un asentamiento estable en la zona. Por el contrario, sí puede afirmarse con seguridad que durante el III milenio cal BC, Tierra Bucho fue objeto de una ocupación intensa que explotó los recursos naturales disponibles y que pese a la localización aleatoria de las cuevas, parece responder a las pautas de un paisaje estructurado. Económicamente, la población encontró en esta media montaña mediterránea "...suficientes recursos como para organizar una relativa autarquía..." (COLÓN DÍAZ, 1998: 190). En este periodo, el posible nexo con otros pastos pirenaicos podría reflejarse en un nuevo hallazgo. Relativamente próxima a la mencionada Cueva Lobrica, pero a bastante mas altura $(1.820 \mathrm{~m})$, se localiza la cueva FP5 en la actual zona de pastos del Puerto Bajo de Góriz en el entorno de Ordesa. En su interior se ha datado ca. 2500 cal BC un hogar en cubeta (D-AMS 015081, 4030 \$33 BP, carbón de Pinus sp.), y en un nivel situado por encima del hogar se han recuperado algunos restos cerámicos carenados: todo indica la frecuentación de estos pastos en las mismas fechas calcolíticas y del Bronce antiguo en que se ocupan Drólica y la Carrasca (LABORDA et al., e.p.).

A partir del 2000 cal BC, como también sucede en los Pirineos catalanes (GASSIOT et al., 2014), este proceso decae, quizás ligado a un descenso de las buenas condiciones ambientales, que se manifiesta en la secuencia de Estaña por el descenso prolongado del quercetal hasta mediados del primer milenio cal BC, o porque cambia por completo el patrón de la ocupación y no hemos sabido/podido rastrear la localización de los asentamientos. Quizás el territorio no se abandone, pero en cualquier caso, la huella arqueológica se debilita en extremo aunque haya un claro impacto antrópico en el registro ambiental (GONZÁLEZ-SAMPÉRIZ et al., 2016): apenas se rastrean en las cuevas ocupaciones, que parecen esporádicas y no de mucha importancia, en la Primera Edad del Hierro (Drólica), en época ibérica o inmediatamente anterior (aparentemente funeraria en Drólica y quizás también en la Carrasca), en cronologías tardorromanas (en la Carrasca)... hasta llegar a un cierto resurgir en el periodo visigodo (restos de ocupación en Drólica y la Carrasca, enterramientos en Foradada) y Alta Edad Media, en la que esta tierra de frontera entre los dominios musulmanes del sur y los valles cristianos del norte se puebla de castillos y torres defensivas y/o de vigilancia.

\section{5.- CONCLUSIONES}

La concentración de trabajos arqueológicos en zonas reducidas permite ensayar interpretaciones históricas. Explicar la significación de un yacimiento en la dinámica de explotación de un territorio en un momento dado exige ampliar el foco hacia estudios holísticos sobre redes de sitios. En el caso de Tierra Bucho, como ya se ha dicho, el objetivo inicial de la investigación fue el estudio de unos trazos parietales localizados en el fondo de cueva Drólica, ante la posibilidad de que fueran humanos. Identificados definitivamente como zarpazos de oso, la atención se centró en el asentamiento calcolítico localizado en el vestíbulo de esta cueva, recurriendo para su contextualización a los datos generados por los trabajos arqueológicos de los años 80 en este entorno, de los que apenas se habían publicados unos someros informes. La tesis doctoral en curso de P. Sánchez responde a este planteamiento, analizando los yacimientos, los materiales recuperados y su organización microespacial (SÁNCHEZ, 2014) y territorial. Otras tesis intervienen sobre algunos restos de los yacimientos de Tierra Bucho: L.M. García Simón está estudiando las variedades litológicas de los sílex; A. Sierra ha comenzado los análisis de fauna a partir de las primeras identificaciones efectuadas por P. Castaños, y M. Alcolea incluye los carbones de Drólica en su tesis sobre antracología, también en fase de redacción.

Pese a haberlo intentado, este estudio presenta una reconstrucción del poblamiento calcolítico de Tierra Bucho que no es completa: a priori, los lugares conocidos (cuevas, dólmenes y, quizás también, abrigos con pinturas) se deberían articular en torno a un(os) asentamiento(s) mayor(es), tipo poblado, que situa$\mathrm{do}(\mathrm{s})$ en el fondo del valle aprovechara(n) la presencia del curso fluvial y las tierras llanas, aptas para el cultivo. Algunos lugares, como La Morería o el pequeño cerro donde se sitúa Santa María de la Nuez, presentan características favorables para la instalación de un poblado calcolítico, aunque hasta el momento no haya sido posible localizar vestigios del mismo.

\section{AGRADECIMIENTOS}

Los autores desean dar las gracias a M. ${ }^{a} \mathrm{~J}$. Calvo por permitir la consulta de toda la documentación de sus excavaciones y a J. Justes por facilitar datos sobre la localización y características de los yacimientos. Este estudio se ha financiado mediante el Proyecto de Investigación HAR2014-59042 (Transiciones climáticas y adaptaciones sociales en la Prehistoria de la Cuenca del Ebro) y el Grupo de Investigación del Gobierno de Aragón H07-PPVE (Primeros Pobladores del Valle del Ebro), y con el soporte del IUCA (Instituto Universitario de Ciencias Ambientales). M. Bea es Investigador Torres Quevedo (ref: PTQ-12-05640), R. Domingo es investigador Ramón y Cajal (ref: RyC201312613), y M. Alcolea es becaria predoctoral (ref: BES 2012-0553828). P. Sánchez ha recibido una Ayuda de Investigación del Instituto de Estudios Altoaragoneses en su convocatoria del 2013 para el estudio de los yacimientos de Tierra Bucho. 


\section{BIBLIOGRAFÍA}

ALCONCHEL, L.

2013 Paleoantropología del alto Vero en el Calcolítico: las cuevas Drólica y de los Cristales y el dolmen de la Caseta de las Balanzas. Bolskan, 24.

ALDAY, A., MONTES, L. y BALDELLOU, V.

2012 El Neolítico en la Cuenca del Ebro. En Rojo, M.: Garrido, R. y García, I. (coords.), El Neolítico en la Península Ibérica y su contexto europeo. Cátedra, Madrid: 291-331.

ANDRÉS, T.

1992 Relaciones Aragón-Litoral Mediterráneo. Sepulcros del Neolítico al Bronce. En Utrilla, P. (coord.) Aragón-Litoral Mediterráneo. Intercambios culturales durante la Prehistoria. Institución Fernando el Católico, Zaragoza: 469-490.

1998 Colectivismo funerario Neo-Eneolítico. Aproximación metodológica sobre datos de la cuenca alta y media del Ebro. Institución Fernando El Católico, Zaragoza. $260 \mathrm{pp}$.

ANDRÉS, T. y BARANDIARÁN, I.

2004 La tumba calcolítica de la Atalayuela, treinta y cinco años después. Saldvie, 4: 85-124.

\section{ARMENDÁRIZ, J., IRIGARAY, S. y ETXEBERRIA, F.}

1994 New evidence of Prehistoric Arrow Wounds in the lberian Peninsula. International Journal of Osteoarchaeology, 4: 215-222.

BADAL, E.

1987 La Antracología: Método de recogida y estudio del carbón prehistórico. Sagvntvm 21: 169-182.

1992 L'anthracologie préhistorique: à propos de certains problèmes méthodologiques. Bulletin de la Société Botanique de France, 139 (2/3/4): 167-189.

BALDELLOU, $\mathrm{V}$.

1986/87 El conjunto de pinturas rupestres post-paleolíticas de la cuenca del Vero. Bajo Aragón Prehistoria, 7-8: 75-84

1987 Avance al estudio de la Espluga de la Puyascada. Bolskan, 4: 3-42.

1991 Memoria de las actuaciones de 1986 y 1987 en la zona del río Vero (Huesca). Arqueología Aragonesa 19861987: $13-17$

BALDELLOU, V., CALVO, M. ${ }^{a}$ J., JUSTE, M. ${ }^{\text {NN }}$ y PARDINILLA, J.I.

2009 Arte rupestre en el río Vero. Comarca de Somontano de Barbastro. Barbastro. 108 pp.

BARANDIARÁN, I.

1973 Restos visigodos en la cueva Foradada (Sarsa de Surta, Huesca). Estudios de la Edad Media de la Corona de Aragón, IX: 9-48.

CALVO, M. ${ }^{\mathrm{J} J}$

1991a Excavaciones en el dolmen de la Caseta de las Balanzas en Selva Grande (Almazorre-Bárcabo, Huesca). Arqueología Aragonesa 1986-1987: 87-88. 1991b Excavaciones en el dolmen de la Capilleta (Paúles de Sarsa, Aínsa, Huesca). Arqueología Aragonesa 19861987: 89-90

CHABAL, L.

1992 La représentativité paléoécologique des charbons de bois archéologiques issus du bois de feu. Bulletin de la société botanique de France, 139 (2/3/4): 213-236.

CLEMENTE, I., GASSIOT, E., REY, J., MAZZUCO, N. y OBEA, L.

2014 "Cort o Transito" -Coro Trasito- o corral de tránsito: una cueva pastoril del Neolítico antiguo en el corazón de Sobrarbe. En: I. Clemente, E. Gassiot y J. Rey (Eds) Sobrarbe antes del Sobrarbe. Pinceladas de historia de los Pirineos: 11-32. Huesca.

COLÓN DÍAZ, M.

1998 Montaña y karst mediterráneo. Especifidad, antropización y gestión ambiental. Universidad de Cádiz, Servicio de publicaciones. Cádiz. 480 pp.

ESCO, C. y CALVO, M.J.

1986 Cueva de la Carrasca (Almazorre-Bárcabo, Huesca). Arqueología Aragonesa 1984: 105-107.

GARCÍA-SIMÓN, L.M. y MANDADO, J.

2014 Rocas silíceas de la margen izquierda del Valle Medio del Ebro. Lucas Mallada, 16: 89-118.

GASSIOT, E.; RODRÍGUEZ, D.; PÈLACHS, A.; BAL, M.C.; GARCIA, V.; JULIÂ, R.; PÉREZ, R. y MAZZUCCO, N

2014 La alta montaña durante la Prehistoria: 10 años de investigación en el Pirineo catalán occidental". Trabajos de Prehistoria, 71(2): 261-281.

GONZÁLEZ-SAMPÉRIZ, P.; ARANBARRI, J.; PÉREZ-SANZ, A GIL-ROMERA, G.; MORENOO, A.; LEUNDA, M.; SEVILLA-CALLEJO, M.: CORELLA, J.P.; MORELLÓN, M.; OLIVA, B. y VALERO-GARCÉS, B.

2016 Environmental and climate change in the southern Central Pyrenees since the Last Glacial Maximum: A view from the lake records. Catena doi:10.1016/j.catena.2016.07.041.

HARRISON, R.J.

1988 Bell Beakers in Spain and Portugal: working with radiocarbon dates in the 3rd millennium BC. Antiquity, 62 464-472. doi:10.1017/S0003598X00074561.

LABORDA, R., VILLALBA-MOUCO, V., LANAU, P., GISBERT, M., DOMINGO R. y MONTES, L.

e.p. El Puerto Bajo de Góriz (Parque Nacional de Ordesa y Monte Perdido). Ocupación y explotación de un paisaje de alta montaña desde la Prehistoria hasta el siglo XX. Bolskan, 26.

MAZZUCO, N., ORTEGA, D., CLEMENTE, I., GASSIOT, E., BALDELLOU, V. y ROJO, M

2014 Pautas de movilidad en el Pirineo central durante el Neolítico antiguo: una aproximación a partir de los recursos líticos. En: I. Clemente, E. Gassiot y J. Rey (Eds) Sobrarbe antes del Sobrarbe. Pinceladas de historia de los Pirineos: 107-126. Huesca 
MONTES, L. y ALDAY, A.,

2012 Enredados en la malla neolítica de la Cuenca del Ebro. Redes, continuidades y cambios. Rubricatum, 5: 51-60.

MONTES, L. y DOMINGO, R.

2014 La ocupación de las Sierras Exteriores durante el Calcolítico. En Utrilla, P. y Mazo, C., La Peña de las Forcas (Graus Huesca). Un asentamiento estratégico en la confluencia del Ésera y el Isábena. Monografías Arqueológicas. Prehistoria 46. Universidad de Zaragoza. Zaragoza: 409-426.

\section{MONTES, L. y MARTÍNEZ BEA, M.}

2006 El yacimiento campaniforme de Cueva Drólica (Sarsa de Surta, Huesca). Saldvie, 6: 297-316.

2007 La Cueva Drólica de Sarsa de Surta (Huesca). El arte rupestre que nunca fue y su yacimiento campaniforme. Veleia, 24-25: 813-831.

MONTES, L.; DOMINGO, R.; SEBASTIÁN, M.; y LANAU, P.

2016 ¿Construyendo un paisaje? Megalitos, arte esquemático y cabañeras en el Pirineo central. ARPI, 04 Extra (Homenaje a R. de Balbín Behrmann): 248-263.

MONTES, L.; MARTÍNEZ BEA, M.; CUCHÍ, J.A. y VILLARROEL, J.L.

2001 Los trazos indeterminados de Cueva Drólica (Sarsa de Surta, Huesca). Bolskan, 18: 233-241.

\section{PALLARUELO, S.}

1988 Pastores del Pirineo. Ministerio de Cultura, Dirección general de Bellas Artes y Archivos. Madrid. 229 pp.

1993 Cuadernos de la trashumancia, n 6: Pirineo aragonés. ICONA, Madrid. 75 pp.

\section{PÉREZ-SANZ, A.}

2014 Holocene climate, vegetation and human impact in the Western Mediterranean inferred from Pyrenean lake records and climate models. Tesis doctoral (inédita). Universidad de Zaragoza, Zaragoza.

PÉREZ-SANZ, A., GONZÁLEZ-SAMPÉRIZ, P., MORENO, A., VALERO-GARCÉS, B., GIL-ROMERA, G., RIERADEVALL, M., TARRATS, P., LASHERAS-ÁLVAREZ, L., MORELLÓN, M., BELMONTE, A., SANCHO, C., SEVILLA-CALLEJO, M. y NAVAS, A.

2013 Holocene climate variability, vegetation dynamics and fire regime in the central Pyrenees: the Basa de la Mora sequence (NE Spain). Quaternary Science Reviews, 73: $149-169$.

REY, J., CLEMENTE, I., y GASSIOT, E.

2014 Cueva Lobrica, hallazgo de un nuevo yacimiento del Neolítico en la orilla izquierda del río Bellós, en el Parque Nacional de Ordesa y Monte Perdido. En: I. Clemente, E. Gassiot y J. Rey (Eds) Sobrarbe antes del Sobrarbe. Pinceladas de historia de los Pirineos: 55-61. Huesca.

\section{SÁNCHEZ, P.}

2014 Tierra Bucho (Huesca): aproximación al análisis microespacial de sus yacimientos prehistóricos. Lucas Mallada, 16: 285-302.
VEGAS, J.I. (coord.)

2007 San Juan ante Portam Latinam: una inhumación colectiva prehistórica en el Valle Medio del Ebro. Memoria de las excavaciones arqueológicas 1985, 1990 y 1991. Colección Barandiarán, 11. Diputación Foral de Álava. Vitoria-Gasteiz. 294 pp.

VEGAS, J.I., ARMENDARIZ, A., ETXEBERRIA, F., FERNÁNDEZ, M.S., HERRASTI, L. y ZUMALABE, F.

1999 La sepultura colectiva de San Juan ante Portam Latinam (Laguardia, Álava) Sagvntvm-PLAV Extra-2 (II Congrés del Neolític a la Península Iberica): 439-445.

ROJO GUERRA, M.A., PEÑA CHOCARRO, L., ROYO GUILLÉN, J.I., TEJEDOR RODRÍGUEZ, C., GARCÍA MARTÍNEŹ DE LAGRÁN, I., ARCUSA MAGALLÓN, H., GARRIDO PENA, R., MORENO-GARCÍA, M., MAZZUCO, N., GIBAJA BAO, J.F., ORTEGA, D., KROMER, B. y ALT, K.W.

2013 Pastores trashumantes del Neolítico Antiguo en un entorno de alta montaña: secuencia crono-cultural de la Cova de Els Trocs (San Feliú de Veri, Huesca). BSAA Arqueología, 79: 9-55.

ROJO GUERRA, M.A., ARCUSA MAGALLÓN, H., PEÑA CHOCARRO, L., ROYO GUILLÉN, J.I., TEJEDOR RODRÍGUEZ, C. GARCÍA MARTÍNEZ DE LAGRÁN, I., GARRIDO PENA, R., MORENO-GARCÍA, M., PIMENTA, C., MAZZUCO, N., GIBAJA' BAO, J.F., PÉREZ JORDÁ, G., JIMÉNEZ JIMÉNEZ, I., IRIARTE, E. y ALT, K.W.

2014 Los primeros pastores trashumantes de la Alta Ribagorza. En: I. Clemente, E. Gassiot y J. Rey (Eds) Sobrarbe antes del Sobrarbe. Pinceladas de historia de los Pirineos: 127-151. Huesca.

VILLAR MARCÉN, J.M.

2006 Biografía de un paisaje: Zuera. Edición del autor, Zuera. $313 \mathrm{pp}$. 